MARIA LUCIANO

ACCOUNTABILITY E ESTADO DEMOCRÁTICO DE DIREITO: CONSTRUINDO LENTES PARA A ANÁLISE DA LEGITIMIDADE DO JUDICIÁRIO NA INCIDÊNCIA EM POLÍTICAS PÚBLICAS

Dissertação de Mestrado

Orientador: Professor Doutor Rafael Diniz Pucci

UNIVERSIDADE DE SÃO PAULO

FACULDADE DE DIREITO

São Paulo - SP

2020 


\title{
ACCOUNTABILITY E ESTADO DEMOCRÁTICO DE DIREITO: \\ CONSTRUINDO LENTES PARA A ANÁLISE DA LEGITIMIDADE DO JUDICIÁRIO NA INCIDÊNCIA EM POLÍTICAS PÚBLICAS
}

\author{
Dissertação de Mestrado
}

Orientador: Professor Doutor Rafael Diniz Pucci

Dissertação apresentada à Banca Examinadora do Programa de Pós-Graduação em Direito, da Faculdade de Direito da Universidade de São Paulo, como exigência parcial para obtenção do título de Mestre em Direito, na área de concentração em Filosofia e Teoria Geral do Direito, sob orientação do Prof. Doutor Rafael Diniz Pucci.

UNIVERSIDADE DE SÃO PAULO

FACULDADE DE DIREITO

São Paulo - SP 
Luciano, Maria

Accountability e Estado Democrático de Direito: construindo lentes para a análise da legitimidade do Judiciário na incidência em politicas públicas ; Maria Luciano; orientador Rafael Diniz Pucci -- São Paulo, 2020 .

55

Dissertação (Mestrado - Programa de Pós-Graduação em Filosofia do Direito e Teoria Geral do Direito) Faculdade de Direito, Universidade de São Paulo, 2020 .

1. judicialização da política. 2. representação política. 3. políticas públicas. 4. legitimidade democrática. 5. crise de representação. I. Pucci, Rafael Diniz, orient. II. Título. 


\section{FOLHA DE APROVAÇÃO}

Nome: Maria Luciano

Título: Accountability e Estado Democrático de Direito: Construindo Lentes para a Análise da Legitimidade do Judiciário na Incidência em Políticas Públicas

Dissertação apresentada à Banca Examinadora do Programa de Pós-Graduação em Direito, da Faculdade de Direito da Universidade de São Paulo, como exigência parcial para obtenção do título de Mestre em Direito, na área de concentração em Filosofia e Teoria Geral do Direito, sob orientação do Prof. Doutor Rafael Diniz Pucci.

Data de Aprovação:

\section{Banca Examinadora}

$\operatorname{Prof(a).~Dr(a).~}$

Instituição:

Assinatura:

Prof(a).Dr(a).

Instituição:

Assinatura:

Prof(a). Dr(a).

Instituição:

Assinatura: 


\section{AGRADECIMENTOS}

Agradeço, primeiramente, a meus pais, sem os quais nada teria sido possível.

Aos amigos, agradeço por todo o apoio e incentivo em seguir quando eu achava que não seria possível. Menciono alguns nomes correndo o risco de cometer a injustiça de esquecer de alguns: Alessandra Gomes, André Coletto, Bárbara Simão, Beatriz Kira, Daniel Murata, Ester Borges, Fernanda Gomes, Gabriel Maia, Heloisa Massaro, Jacqueline Abreu, Lucca Rett, Mariana Buzzo, Paula Pécora e Walter Cancelieri.

À Cinthia Vernus e Camila Villard pela acolhida e escuta em momentos difíceis.

Ao InternetLab, em especial Mariana Valente e Francisco Brito Cruz, pelas oportunidades e espaço de crescimento e aprendizagem.

Ao Bruno Ricardo Bioni, pela parceria e por toda a generosidade em ensinar.

Aos participantes da Sixth Conference for Junior Researchers "Backwards and Forwards: Law in a Time of Crisis”, em especial Alicia Pastor, pelos inputs e inspiração contagiantes.

Aos organizadores do grupo "Atores judiciais e decisões políticas" da ANPOCS, pela oportunidade de discutir as ideias, tão incompletas, que iniciaram essa pesquisa.

Às professoras Regina Vera Villas Bôas e Patrícia Nunes Lima Bianchi pelos comentários feitos por ocasião da minha banca de qualificação.

Por fim, ao professor Rafael Diniz Pucci, pela oportunidade de ingressar no programa de pós-graduação e me mostrar o tipo de pesquisadora que quero ser.

Obrigada por acreditarem em mim, inclusive quando eu mesma não o faça. 
Àqueles que me ensinaram a amar (em memória). 
"Se existe um núcleo normativo próprio da democracia, ele está antes no princípio de que a dinâmica institucional deve poder ser colocada em questão em todos os seus diferentes momentos, em seus diferentes desenhos, um questionamento que deve poder ser levado a seus limites tanto por demandas concretas dirigidas a este ou aquele órgão, como na dimensão mais abstrata do debate acadêmico, ou do questionamento judicial e da disputa legislativa” (NOBRE e RODRIGUEZ, 2011, p. 12). 


\section{RESUMO}

LUCIANO, Maria. Accountability e Estado Democrático de Direito: Construindo Lentes para a Análise da Legitimidade do Judiciário na Incidência em Políticas Públicas. 2020. 55 f. Dissertação (Mestrado) - Departamento de Filosofia e Teoria Geral do Direito, Faculdade de Direito, Universidade de São Paulo, São Paulo, 2020.

A pesquisa tem como objeto a legitimidade democrática de decisões judiciais acerca de políticas públicas. Buscando novas abordagens a essa discussão, realiza um esforço interdisciplinar ao propor uma aproximação entre o debate acerca da judicialização da política e aquele sobre representação política na teoria democrática contemporânea. Tem como hipótese a existência de ganhos analíticos e teóricos em se atualizar a noção de legitimidade democrática para além daquela conferida pelo voto eleitoral (binômio autorização - accountability). O argumento central é o de que a falta de legitimidade democrática dessas decisões não decorre do fato de juízes não serem eleitos, mas sim da ausência de desenhos institucionais que garantam essa legitimidade por outros elementos que não o voto eleitoral.

Palavras-chave: judicialização da política; políticas públicas; legitimidade democrática; representação política; crise da representação. 


\begin{abstract}
LUCIANO, Maria. Accountability and Democratic State: Building Lens to Analyze the Judiciary's Legitimacy in Decisions on Public Policies. 2020. 55 p. Dissertation (Master) - Department of Philosophy and General Theory of Law, Law School, University of São Paulo, São Paulo, 2020.
\end{abstract}

The research has as its object the democratic legitimacy of judicial decisions concerning public policies. Seeking new approaches to this discussion, it makes an interdisciplinary effort by proposing an approximation between the debate on the judicialization of policies and that on political representation within contemporary democratic theory. It hypothesizes the existence of analytical and theoretical gains in updating the notion of democratic legitimacy beyond that conferred by the electoral vote. The argument is that the lack of democratic legitimacy of these decisions does not lie in the fact that judges are not elected, but rather in the absence of institutional designs that guarantee this legitimacy by elements other than electoral voting.

Keywords: judicialization of politics; public policies; democratic legitimacy; political representation; crisis of representation 


\section{ÍNDICE}

INTRODUÇÃO ............................................................................................................11

CAPÍTULO 1. A "JUDICIALIZAÇÃO DA POLÍTICA" ENQUANTO

CATEGORIA DE ANÁLISE .................................................................................14

1.1. Diagnóstico das pesquisas no tema .................................................................................14

1.2. O que é e o que provoca a judicialização da política? ..............................................19

1.3. Críticas à judicialização da política...............................................................................23

1.4. Conclusão parcial.................................................................................................................25

CAPÍTULO 2. REPRESENTAÇÃO POLÍTICA E LEGITIMIDADE DEMOCRÁTICA: PARA ALÉM DO VOTO ELEITORAL ...........................................28

2.1. Crise de Representação? ................................................................................................28

2.2. Legitimidade democrática e governos representativos .............................................31

2.3. Conclusão parcial...........................................................................................................35

CAPÍTULO 3. LEGITIMIDADE DEMOCRÁTICA EM DECISÕES JUDICIAIS: O PAPEL DO DIREITO NA CONSTRUÇÃO DE DESENHOS INSTITUCIONAIS

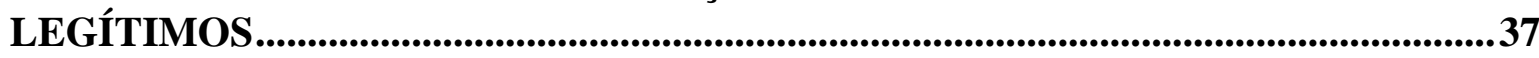

3.1. A judicialização da educação infantil na cidade de São Paulo .................................38

3.2. Conclusão parcial.............................................................................................................46

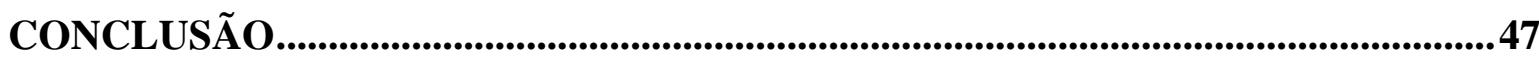

BIBLIOGRAFIA ….........................................................................................................49 


\section{INTRODUÇÃO}

A Constituição Federal de 1988 conferiu ao Judiciário status de agente político. Esse novo cenário atraiu as atenções de pesquisadores da Ciência Política e do Direito, que realizaram suas análises por meio das categorias de "judicialização da política" e "ativismo judicial", a elas atribuindo significados fluidos e até mesmo divergentes. Todavia, tais esforços, se não se utilizam de uma definição única do que seja a judicialização, parecem compartilhar da perspectiva da teoria democrática liberal como pressuposto, para a qual o princípio da separação de poderes é tão caro. E essa abordagem tem tido por consequência a adoção de uma visão maniqueísta desse fenômeno, a qual resume-se a endossá-lo ou criticálo.

Para além do pouco potencial teórico e analítico dessa abordagem para uma melhor compreensão da judicialização de políticas enquanto objeto de estudo do Direito, suas críticas merecem ainda uma atualização. Baseadas na ideia de que juízes, e instituições não majoritárias como um todo, não deteriam legitimidade democrática por não terem sido eleitos pelo povo, tais críticas parecem desconhecer ou ignorar os últimos desdobramentos das discussões sobre representação política que têm tomado a Ciência Política.

O surgimento do conceito de representação política está relacionado à soberania do poder político, definida pela perspectiva liberal-contratualista como a capacidade de agir com autoridade por meio da autorização. De modo semelhante ao paralelo soberania/liberdade individual que a representação política buscou responder, as eleições foram concebidas, pelo pensamento liberal, como a forma de governo que melhor responderia à conciliação entre esfera pública e esfera privada. Elas permitiriam o exercício da soberania individual e garantiriam um sistema de freios e contrapesos que preveniria a corrupção e o abuso de poder.

A histórica associação entre democracia e representação surgida daí tem sido refutada pela teoria democrática contemporânea, diante do surgimento de novas formas de representação política que se desenvolvem em domínios da política não-eleitoral e desafiam a noção tradicional de representação política associada a princípios como delegação, igualdade matemática e monopólio territorial. Essas experiências obtêm sua legitimidade 
democrática em elementos outros que não o voto. E é nela que têm se fundado as discussões a respeito da legitimidade de decisões judiciais em políticas públicas.

A presente dissertação propõe uma aproximação entre esses dois debates - acerca da judicialização da política e representação política - tendo como hipótese a existência de ganhos analíticos e teóricos em se atualizar a noção de legitimidade democrática das decisões judiciais sobre políticas públicas. ${ }^{1} \mathrm{O}$ argumento central é o de que a falta de legitimidade democrática dessas decisões não decorre do fato de juízes não serem eleitos, mas sim da ausência de desenhos institucionais que garantam essa legitimidade por outros elementos que não o voto eleitoral.

A interdisciplinaridade proposta e defendida neste trabalho decorre da ideia de que a sociologia jurídica seria uma alternativa ao isolamento do direito em relação a outras ciências humanas, bem como à confusão entre prática profissional e pesquisa acadêmica características do campo (NOBRE, 2005, p. 04). Afinal, a despeito da frequente identificação da sociologia jurídica como disciplina descritiva, com foco na eficácia do direito (e não na sua validade como as demais disciplinas), a constituição do campo decorreu de incômodos críticos, da percepção de que a constituição do saber jurídico deixava de atentar para os conflitos que se produzem no direito (FARIA, 1988).

Para além da desafiadora tarefa de adentrar um novo campo - engajando com novos autores -, propõe-se pensar sobre a organização institucional do poder Judiciário, concebendo o direito como instrumento de imaginação institucional (UNGER, 1996). A coordenação e a atribuição de responsabilidades, mandatos ou competências aos atores políticos é feita por arranjos institucionais, que viabilizam a articulação entre os atores direta e indiretamente ligados às políticas públicas (COUTINHO, 2016). Com a juridificação de direitos sociais na $\mathrm{CF} / 88$, cabe realizar esse exercício a respeito do Judiciário, desde então inserido na arena política.

Esta dissertação é composta por três capítulos, além desta introdução e de uma conclusão. No primeiro deles, mapearemos as definições desenvolvidas, abordagens

\footnotetext{
${ }^{1}$ Visando evitar confusões sobre a proposta do presente trabalho, esclarecemos que é esse aspecto do fenômeno maior de judicialização da política que interessa a esta pesquisa, a revisão judicial de atos ou omissões do Poder Executivo no desenvolvimento de políticas sociais.
} 
metodológicas adotadas e condicionantes apontas a respeito da judicialização da política. A despeito dos usos múltiplos da expressão, das limitações das metodologias comumente empregadas e da falta de diálogo entre os autores, as pesquisas nesse tema parecem tangenciar o diagnóstico de crise de representação política das instituições majoritárias, em alta na Ciência Política. Todavia, elas não respondem em que se fundamentaria a atuação dos tribunais enquanto alternativa, i. e. sua legitimidade democrática enquanto instituição não-majoritária.

No segundo capítulo, apresentaremos o debate acerca do conceito de representação política que tem tomado a Ciência Política nas últimas décadas. Inicialmente atrelado à soberania do poder político, i. e. a capacidade de agir com autoridade por meio da autorização, esse conceito foi associado de maneira necessária às eleições pela teoria democrática liberal. O voto seria o ato por meio do qual a autorização dos representados seria dada ao representante, bem como aqueles realizariam a accountability das ações políticas deste. Constituiria, assim, a legitimidade democrática da relação de representação. Todavia, a teoria democrática contemporânea tem questionado essa associação direta entre representação e eleições, que não contempla diversas experiências, significados e contextos da atividade representativa que estão fora do contexto eleitoral. Esses novos desdobramentos do debate têm como pano de fundo a crise de representação política que tem acometido as instituições majoritárias. Nesse sentido, questiona-se o binômio autorização - accountability como condição suficiente para tornar uma relação representativa democrática.

Finalmente, no terceiro e último capítulo discutiremos as possíveis contribuições do direito à configuração democrática de relações representativas, notadamente enquanto instrumento de imaginação institucional e ferramenta de construção de arranjos institucionais.

Isto posto, passemos ao primeiro capítulo. 


\section{CONCLUSÃO}

No primeiro capítulo buscamos apresentar um panorama das discussões a respeito da judicialização da política. Fazê-lo nos permitiu identificar alguns pontos que demandam avanços, bem como nos forneceu pistas de por onde começar a endereçá-los.

Foi a partir da constatação dos problemas de representação política e legitimidade democrática discutidos no estado da arte do debate, que se realizou uma aproximação interdisciplinar com a teoria democrática contemporânea. Se por um lado, o Direito pode encontrar respostas às limitações teóricas e analíticas que ainda não conseguiu endereçar; por outro lado, esse debate da Ciência Política precisa do Direito enquanto ferramenta para construir arranjos jurídicos que garantam instâncias de representação política, de fato, democráticas.

No segundo capítulo, apresentamos o debate sobre representação política. Esse esforço deveu-se ao fato de o diagnóstico de crise da representação ser o ponto de partida de ambas as agendas de pesquisa. Endereçar esse problema exigiu a revisão do conceito de representação política, de tradição liberal-contratualista, há tanto arraigado no debate público. O momento autorizativo estabelecido pelo voto eleitoral não consegue mais conferir o caráter democrático da representação. As formas dinâmicas e substantivas de representação política, que se preocupam com a representatividade do que ocorre durante a representação, parecem contornar esses problemas trazidos pela crise.

Finalmente, no terceiro e último capítulo, buscamos jogar luz sobre o potencial do direito, enquanto ferramenta estruturante de arranjos institucionais, poder criar e reconfigurar as dinâmicas representativas úteis a uma representação democrática. Assim, a falta de legitimidade democrática de decisões judiciais em políticas públicas não decorreria do fato de juízes não serem eleitos pelo povo, mas da ausência de arranjos institucionais que ajudem a construir essa legitimidade por outras dinâmicas.

A proposta de aproximação e de mobilização de categorias da teoria democrática contemporânea para a discussão da legitimidade democrática do Judiciário não traz respostas definitivas - essa nunca foi a intenção. Ela procura, por outro lado, apontar novos caminhos e reformulações do problema, abrindo, assim, uma agenda de pesquisa ainda a ser explorada. 
Os direitos sociais, ao demandarem expressiva prestação estatal, extrapolam os limites do raciocínio jurídico-formal na busca pela sua garantia. Nesse sentido, é preciso atualizar os pressupostos e revisar as estratégicas jurídicas herdadas da tradição do sistema do Civil Law, bem como da transposição "à brasileira" de tradições constitucionais e representativas liberais do norte.

Tendo em vista que os critérios, padrões e balizas da justiça são definidos histórica e socialmente, pois são estabelecidos e desafiados pela ação social, coloca-se o desafio da permanente reconstrução da definição de justiça, o que demanda a participação dos atores sociais e o desenvolvimento de gramáticas morais capazes de considerar os outros como interlocutores (AVRITZER e MAROA, 2014, p. 79).

Soma-se a isso o crescente agravamento da crise de representatividade, a despeito da abertura do sistema político diante da pressão de movimentos sociais e outros atores societais a partir do processo de redemocratização.

Nesse cenário, a busca por direitos e pelo exercício da soberania popular - seja por conta do intervalo temporal das eleições, seja pela ausência de representatividade dos representantes eleitos - tem extrapolado as instituições majoritárias. Modelos de representação que se preocupem com o teor substantivo das atividades dos representantes (i. e. com o que acontece durante a representação eleitoral), bem como com a representatividade dos valores em constante mudança na sociedade, são desafiadores, mas parecem alternativa válida na tentativa de resolução desses problemas.

Ao estabelecer direitos, competências e estruturar instituições, parece necessário que o Direito acompanhe esse movimento para dar-lhe efetividade, o que inicia com o acompanhamento dessas discussões.

As dificuldades aqui apontadas parecem indicar que, para fins de avanço em questões de tamanha complexidade, o insulamento do campo não contribuirá nem para um Estado democrático, nem para um Estado de direito. 


\section{BIBLIOGRAFIA}

ABRAMOVICH, Victor. Linhas de trabalho em direitos econômicos, sociais e culturais: instrumentos e aliados. SUR - Revista Internacional de Direitos Humanos, ano 2, no. 2, 2005.

ALEXY, Robert. Constitucionalismo discursivo. Porto Alegre: Livraria do Advogado, 2007.

ALMEIDA, Debora Cristina Rezende de. A relação contingente entre representação e legitimidade democrática sob a perspectiva da sociedade civil. Revista Brasileira de Ciências Sociais, vol. 28, no. 82, 2013.

Repensando representação política e legitimidade democrática. 2011. Tese

(Doutorado) - Faculdade de Filosofia e Ciências Humanas da Universidade Federal de Minas Gerais, Belo Horizonte.

ARANTES, Rogério Bastos. Ministério Público e política no Brasil. São Paulo: Editora Sumaré, 2002.

Judiciário: entre a Justiça e a Política. In: AVELAR, Lúcia; CINTRA, Antônio Octavio. (Org.). Sistema político brasileiro: uma introdução. São Paulo: Editora UNESP, 2007.

AVRITZER, Leonardo; MARONA, Marjorie Corrêa. Judicialização da Política no Brasil: ver além do constitucionalismo liberal para ver melhor. Revista Brasileira de Ciência Política, no. 15 , Brasília, setembro - dezembro 2014.

BARROSO, Luís Roberto. Judicialização, ativismo judicial e legitimidade democrática. In: COUTINHO, Jacinto Miranda; FRAGALE, Roberto; LOBÂO, Ronaldo (Org.). Constituição e ativismo judicial: limites e possibilidades da norma constitucional e da decisão judicial. Rio de Janeiro: Lumen Juris, 2011.

CAMPILONGO, Celso Fernandes. Os desafios do Judiciário: um enquadramento teórico. In: FARIA, José Eduardo (org.). Direitos Humanos, Direitos Sociais e Justiça. São Paulo: Malheiros, 1994.

CAPPELLETTI, Mauro. Juízes legisladores? Porto Alegre: Fabris, 1999. 
CARVALHO, Ernani Rodrigues de. Em Busca da Judicialização da Política no Brasil: Apontamentos para uma Nova Abordagem. Revista de Sociologia e Política, 23, Curitiba, nov., 2004.

CASTRO, Marcos Faro de. O Supremo Tribunal Federal e a judicialização da política. Revista Brasileira de Ciências Sociais, v. 12, no. 34, São Paulo, 1997.

CORREA, Luiza Andrade. A judicialização da política pública de educação infantil no Tribunal de Justiça de São Paulo. 2014. Dissertação (Mestrado) - Faculdade de Direito da Universidade de São Paulo, São Paulo.

COUTINHO, Diogo R. O Direito Econômico e a Construção Institucional do Desenvolvimento Democrático. Revista Estudos Institucionais, vol. 2, no. 1, 2016.

DAHL, Robert. A prefacy to democratic theory. Chicago: The University of Chicago, 1956.

DUARTE, Guilherme Jardim; VASCONCELOS, Natália Pires de; MARTINS, Rodrigo; QUEIROZ MOREIRA, Thiago de Miranda. O Sistema de Justiça na Ciência Política Brasileira: uma análise da literatura. set., 2015. Disponível em < https://papers.ssrn.com/sol3/papers.cfm?abstract_id=2886646 >, acesso em 05.08.2019.

FARIA, José Eduardo. Direito e justiça no século XXI: a crise da justiça no Brasil. 2003. Disponível em: < https://www.ces.uc.pt/direitoXXI/comunic/JoseEduarFaria.pdf >, último acesso em 11.08.2018.

- Eficácia jurídica e violência simbólica: o direito como instrumento de transformação social. São Paulo: EDUSP, 1988.

. O Direito na economia globalizada. São Paulo: Malheiros, 2002.

. O Judiciário e os Direitos Humanos e Sociais: Notas para uma Avaliação da Justiça Brasileira. In: FARIA, José Eduardo (org.). Direitos Humanos, Direitos Sociais e Justiça. São Paulo: Malheiros, 2010.

FEREJOHN, John. Judicializing Politics, Politicizing Law. Journal of Law and Contemporary Problems, v. 65, no. 3, 2002. 
FONTES, Paulo Gustavo Guedes. A Ação Civil Pública e o princípio da separação dos poderes: estudo analítico de suas possibilidades e limites. In: MILARÉ, Edis (Coord.). A Ação Civil Pública após 20 anos: efetividade e desafios. São Paulo: Ed. Revista dos Tribunais, 2005.

GOUVÊA, Marco Maselli. Balizamentos da Discricionariedade Administrativa na Implementação dos Direitos Econômicos, Sociais e Culturais. In: GARCIA, Emerson (Coord.). Discricionariedade Administrativa. Rio de Janeiro: Lúmen Júris, 2005.

HIRSCHL, Ran. The new constitutionalism and the judicialization of pure politics worldwide. Fordham Law Review, v. 75, no. 2, 2006.

HOBBES, Thomas. Leviatã: ou matéria, forma e poder de um Estado eclesiástico e civil. São Paulo: Nova Cultural, 1997. (Coleção Os Pensadores).

IBAÑEZ, Perfecto Andrés. Democracia com juízes. Revista do Ministério Público, ano 24, no. 94, Lisboa, jun./2003.

KELSEN, Hans. Teoria pura do direito. 6 ed. São Paulo: Martins Fontes, 1998.

KOERNER, Andrei; INATOMI, Celly Cook; BARATTO, Márcia. Sobre o Poder Judiciário e a Judicialização. In: MOTTA, Luiz Eduardo; MOTA, Mauricio (Org.). O Estado Democrático de Direito em questão: teorias críticas da judicialização da política. Rio de Janeiro: Elsevier, 2011.

LAVALlE, Adrián Gurza.; HOUTZAGER, Peter P.; CASTELLO, Graziela. Democracia, pluralização da representação e sociedade civil. Lua Nova, Revista de Cultura e Política, no. 67, 2006.

LOPES, José Reinaldo de Lima. Direitos Sociais: teoria e prática. São Paulo: Método, 2006.

LOUREIRO, Maria Rita. Interpretações contemporâneas da representação. Revista Brasileira de Ciência Política, no. 1, Brasília, jan./jun. 2009.

MACIEL, Débora Alves. Ação Coletiva, Mobilização do Direito e Instituições Políticas: o caso da Campanha da Lei Maria da Penha. Revista Brasileira de Ciências Sociais, vol. 26, no. $77,2011$. 
MACIEL, Débora Alves; KOERNER, Andrei. Sentidos da Judicialização da Política: duas análises. Lua Nova, Revista de Cultura e Política, no. 57, 2002.

MANIN, Bernard. The principles of representative government. Cambridge: Cambridge University, 1997.

NOBRE, Marcos. Apontamentos sobre a pesquisa em direito no Brasil. Cadernos Direito GV, vol. 1, no. 1, 2005.

; RODRIGUEZ, José R. Judicialização da política: déficits explicativos e bloqueios normativistas. Revista Novos Estudos, CEBRAP, no. 91, São Paulo, nov., 2011.

NUNES JUNIOR, Amandino Teixeira. A judicialização da política no Brasil: análise das decisões do TSE do STF sobre a verticalização das coligações e fidelidade partidária. 2014. Tese (Doutorado) - Instituto de Ciência Política da Universidade de Brasília, Brasília.

PARKINSON, John. Legitimacy problems in deliberative democracy. Political Studies, vol. $51,2003$.

PIETRO, Maria Sylvia Zanella di. Discricionariedade administrativa na Constituição de 1988. 2 ed. São Paulo: Atlas, 2007.

PITKIN, Hanna F. The concept of representation. Berkeley e Los Angeles: University of California, 1967.

POGREBINSCHI, Thamy. Judicialização ou Representação? Rio de Janeiro: Elsevier, 2011.

; SANTOS, Fabiano. Contra a falácia da crise institucional: conferências nacionais de políticas e o impacto (positivo) sobre o congresso. Revista Insight Inteligência, n. 49, abr./jun, 2010.

RIZZI, Ester; SALOMÃO, Ximenes. Litigância estratégica para a promoção políticas públicas: as ações em defesa do direito à educação infantil em São Paulo. In: FRIGO, Darci; PRIOSTE, Fernando; ESCRIVÃO FILHO, Antônio Sérgio. Justiça e Direitos Humanos: Experiências de Assessoria Jurídica Popular. Curitiba: Terra de Direitos, 2010. 
RIZZI, Ester; SALOMÃO, Ximenes. Litígio estratégico para a mudança do padrão decisório em direitos sociais: ações coletivas sobre educação infantil em São Paulo. $8^{\circ}$ Encontro da ANDHEP - Políticas Públicas para a Segurança Pública e Direitos Humanos, 2014.

ROSANVALlON, Pierre. Por uma história do político. Tradução Christian Edward Cyril Lynch. São Paulo: Alameda, 2010.

SADEK, Maria Teresa. Poder Judiciário: seu panteão. Revista Brasileira de Estudos Constitucionais, ano 1, no. 1, jan./mar., 2007.

SALLES, Carlos Alberto de. Ação civil pública contra omissões do poder público: limites e possibilidades. In: SALLES, Carlos Alberto de (org). Processo civil e interesse público: o processo como instrumento de defesa social. São Paulo: Ed. Revista dos Tribunais, 2003.

SANTOS, Boaventura de Sousa. A judicialização da política. Center for Social Studies, 2003. Disponível em < https://www.ces.uc.pt/ces/opiniao/bss/078.php >, último acesso em 20.10.2018.

SANTOS, Boaventura de Souza. Direito e democracia: a reforma global da justiça. Porto: Afrontamento, 2001.

SILVA, José Afonso. Aplicabilidade das normas constitucionais. 6 ed. São Paulo: Malheiros, 2002.

TATE, C. Neal; Why the Expansion of Judicial Power? In: TATE, C. Neal; VALLINDER, Torbjorn. (org.). The Global Expansion of Judicial Power. New York: New York University, 1995.

TAYLOR, Matthew M. O judiciário e as políticas públicas no Brasil. Revista Dados, vol. 50, no. 02, Rio de Janeiro, 2007.

; DA ROS, Luciano. Os partidos dentro e fora do poder: a judicialização como resultado contingente da estratégia política. Revista Dados, v. 51, no. 4. Rio de Janeiro, 2008 . 
TEIXEIRA, Ariosto. A judicialização da política no Brasil (1990-1996). 1997. Dissertação

(Mestrado) - Instituto de Ciência Política da Universidade de Brasília, Brasília.

UNGER, Roberto Mangabeira. Legal Analysis as Institutional Imagination. The Modern Law Review, v. 59, n. 1, jan., 1996.

URBINATI, Nadia. O que torna a representação democrática? Lua Nova, Revista de Cultura e Política, São Paulo, v. 67, 2006.

; WARREN, Mark E. The concept of representation in contemporary democratic theory. Annual Review of Political Science. n. 11, 2008.

VERBICARO, Loiane Prado. Um estudo sobre as condições facilitadoras da judicialização da política no Brasil. Revista Direito GV, 4 (2), jul - dez, 2008.

VERÍSSIMO, Marcos Paulo. Controle Judicial da Atividade Normativa das Agências de Regulação Brasileiras. In: ARAGÃO, Alexandre Santos de. (Org.). Poder Normativo das Agências de Regulação. Rio de Janeiro: Editora Forense, 2006.

VIANNA, Luís Werneck; CARVALHO, Maria Alice Rezende de; MELO, Manuel Palacios Cunha; BURGOS, Marcelo Baumann. A judicialização da política e das relações sociais no Brasil. Rio de Janeiro: Editora Revan, 1999.

VIANNA, Luiz Werneck. A democracia e os três poderes no Brasil. Belo Horizonte: Ed. UFMG; Rio de Janeiro: IUPERJ/FAPERJ, 2003.

VIANNA, Luiz Werneck. A judicialização da política. In: AVRITZER, Leonardo; BIGNOTTO, Newton; FILGUEIRAS, Fernando; GUIMARÃES，Juarez; STARLING, Heloísa (Org). Dimensões políticas da justiça. Rio de Janeiro: Civilização Brasileira, 2013.

VIEIRA, Oscar Vilhena. Experimentalismo Judicial. Folha de São Paulo, 03 de maio de 2014. Disponível em < https://www1.folha.uol.com.br/colunas/oscarvilhenavieira/2014/05/1448931experimentalismo-judicial.shtml >, último acesso em 01.05.2017. 
WANG, Daniel Wei Liang. Poder Judiciário e participação democrática nas políticas públicas de saúde. 2009. Dissertação (Mestrado) - Faculdade de Direito da Universidade de São Paulo, São Paulo.

WERNECK ARGUELHES, Diego; MOLHANO RIBEIRO, Leandro. Contextos da Judicialização da Política: novos elementos para um mapa teórico. Revista Direito GV, vol. 15, no. $2,2019$.

YOUNG, Iris Marion. Inclusion and democracy. Oxford: Oxford University, 2000.

YOUNG, Iris Marion. Representação política, identidades e minorias. Lua Nova, Revista de Cultura e Política, São Paulo, no. 67, 2006. 